\title{
La Ecloga de aduentu proregis Ludouici de Velasco del Ms. 1631 (BNM): Género de circunstancia y modelo virgiliano
}

\author{
Marcela A. Suárez*
}

\section{Recibido: 27 de enero de 2015}

Evaluado: 28 de junio de 2014

El manuscrito 1631 de la Biblioteca Nacional de México es la fuente más rica para el conocimiento de la literatura neolatina novohispana de los siglos XVI y XVII, pues permite abordar el ambiente y el estado literarios del último cuarto del siglo XVI en los colegios jesuíticos. Tras haber pertenecido probablemente al colegio de San Pedro y San Pablo, pasa en 1767, luego de la expulsión de los jesuitas, a la biblioteca de la Real y Pontificia Universidad. En el siglo XIX los fondos de esta biblioteca se transforman en fondos de origen de la Biblioteca Nacional y el códice se incorpora a la sección "Manuscritos". De procedencia jesuítica según parece, el manuscrito novohispano incluye textos en latín escritos con motivo de festividades religiosas, certámenes literarios o actos sociales. La producción de estas composiciones se ubica entre 1585, año en el que se lleva a cabo el Concilio mexicano, y 1629, año del certamen convocado para la canonización de San Felipe de Jesús. Entre los textos más destacados que el manuscrito presenta, cabe mencionar un corpus de 10 églogas escritas en latín comprendidas entre los folios 109r y 115r. En esta ocasión nos interesa analizar, sobre la base del modelo virgiliano, la égloga compuesta a propósito de la llegada del virrey Luis de Velasco.

Ijsewijn, al referirse a la literatura neolatina, afirma: "Every literary form, genre, theme and even minor peculiarity which can be found in ancient Latin and Greek literature has seeped into neo-Latin in one way or another” ${ }^{1}$.

En este sentido, no sorprende que el denominador genérico de esta sección del manuscrito sea la égloga, pues de todos los géneros poéticos transmitidos por la antigüedad, después de la elegía y el epigrama, el género bucólico es el más cultivado por los poetas neolatinos ${ }^{2}$.

\footnotetext{
* CONICET -UBA.

${ }^{1}$ Ijsewijn, 1977: 262.

${ }^{2}$ Van Thiegem, 1966.
} 
Siguiendo el principio básico de la imitatio et aemulatio ueterum que caracteriza a la literatura humanística, Virgilio es el summus poeta, "el más estudiado e imitado en

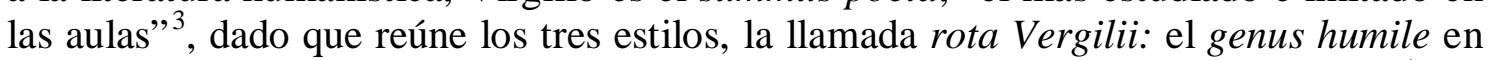
las Bucólicas, el genus medium en las Geórgicas y el genus sublime en la Eneida ${ }^{4}$ La imitación de la poesía bucólica cumple una función propedéutica en el Renacimiento. Al discurso pastoril acceden tempranamente los alumnos avanzados de Studia Humanitatis, a través del análisis, traducción o paráfrasis de las églogas del mantuano. ${ }^{5}$

La égloga es, sobre todo, un poema cuya materia consta de un encuadre ambiental constituido por un escenario boscoso y personajes "pastores". Dicho encuadre se convierte en el elemento definitorio y esencialmente bucólico. El contenido enmarcado en ese ambiente puede relacionarse con las formas genéricas preexistentes, es decir, con la elegía (quejas amorosas o fúnebres, por el amor desdichado o por la muerte de alguien), la épica (canciones míticas o heroicas o narrativo-panegíricas), el epigrama (coplas cortas, estructuradas en clímax, y engarzadas en series, dentro del carmen amebeo), el drama en su variedad de mimo (diálogos entre pastores, sin canto propiamente dicho). Por tal razón, es posible hablar no de contaminación de géneros, sino más bien de la égloga como género-marco. Estamos, pues, frente a un género peculiar, que no viene precisado ni por sus marcas discursivas, ni retóricas, ni métricas, elementos decisivos en la conformación de los géneros poéticos, y cuya delimitación, desde el punto de vista conceptual, puede establecerse si se observa el campo temático y la actitud del sujeto poético. Sin embargo, dado que el repertorio temático resulta muy variado, según se ha señalado, lo determinante entonces no es tanto el tema como el tono o, en todo caso, la actitud. En este sentido, la égloga puede dividirse en dos grupos: uno de modalidad elegíaca ${ }^{6}$ y otro de tono y finalidad circunstancial.

Perfilar un panorama de la égloga como género de circunstancias en los siglos XVI y XVII implica, ante todo, definir qué es un poema de circunstancias ${ }^{7}$. Los poemas de circunstancias son aquellos que se producen en el marco de las justas y academias y los que apuntan a celebrar figuras o acontecimientos de dimensiones públicas ${ }^{8}$. Esto permite explicar el hecho de que, a partir del Renacimiento, dentro del cuadro genérico pastoral, un amplio número de escritores neolatinos utilice la égloga como un medium o como el género-marco para abordar sucesos históricos y políticos 9 .

En el contexto de la sociedad colonial, se destacan dos hechos relevantes: las juntas eclesiásticas y la llegada de los virreyes. La reunión de juntas eclesiásticas es una

\footnotetext{
${ }^{3}$ Osorio Romero, 1980: 57.

${ }^{4}$ González Vázquez, 1991: 133.

${ }^{5}$ El sistema pedagógico jesuítico denominado Ratio Studiorum (1599) propone en las clases de Humanidades y de Gramática el estudio de una serie de autores en su mayoría latinos, necesarios para garantizar la buena formación de los estudiantes. En estas áreas la lectura, memorización e imitación de la poesía latina ocupa un lugar relevante. Se aconsejaban expresamente Virgilio, Ovidio, Horacio, Seneca, Marcial, Tibulo, Propercio, Terencio, Estacio, Claudiano, Galo, Ausonio e, incluso, Catulo y Plauto, siempre expurgados en ediciones ad usum scholarum Societatis Iesu (Gil, 1992).

${ }^{6}$ Acerca de esta modalidad, ver Suárez, 2012.

${ }^{7}$ Osuna, 2008: 357.

${ }^{8}$ En España este tipo de égloga se utilizó para celebrar la venida de la princesa doña Juana y Felipe el Hermoso, la victoria del Gran Capitán en Orán, la llegada de Carlos V a Valladolid o la victoria de Pavía sobre el rey de Francia (Osuna, 2008).

${ }^{9}$ Grant, 1965.
} 
práctica frecuente durante el siglo XVI orientada a la resolución de problemas concretos, derivados de las dificultades en la evangelización y la organización de la Iglesia novohispana. Con respecto a los virreyes, en Nueva España la trayectoria de los mandatarios desde Veracruz hasta la capital se caracteriza por múltiples actos y la entrada en la ciudad de México está marcada por la mayor solemnidad y el máximo esplendor.

El Ms. 1631 de la BNM presenta un grupo de églogas escritas justamente para conmemorar ambos sucesos, pero en esta ocasión sólo abordaremos el análisis de la égloga dedicada a la llegada del virrey Luis de Velasco, conocido como el Hijo, el Joven o el Segundo ${ }^{10}$, el 25 de enero de 1590. Acerca de este acontecimiento, escribe Osorio Romero: "La ciudad de México determinó hacer variados festejos como escaramuzas en el valle de Guadalupe; organizó juegos de cañas y corridas de toros; convirtió la plaza mayor de la ciudad en un bosque con venados y conejos; levantó un arco triunfal y recibió al virrey bajo palio de seda. La Compañía, por su parte, con la ayuda económica del Cabildo representó una comedia cuyo tema desconozco y fijó poemas alusivos a la ocasión. Los autores, al igual que los que les leyeron, recibieron $\$ 400$ de premios"11.

En alusión a este hecho de singular relevancia el Ms. 1631 conserva la égloga $8^{12}$ que transcribimos a continuación:

\section{Ecloga de aduentu proregis Ludouici de Velasco Coridon/Thyrsis}

THY. Linque tuas Coridon tondentes rura capellas uocibus alternis alternent carmina Daphnin.

COR. Daphnin ad astra feramus, amauit nos quoque Daphnis

occiduo decus egregium spesque unica mundo.

THY. Vera mihi Coridon, nam me dum silua recondit 5

Illum per campos perque urbem fusa iuuentus

Cuncta replens sonitu resonat, resonantque Camenae

usque adeo ut siluis Coridon iam nil nisi Daphnis.

COR. Saepius argutae recolo sub tegmine pinus

Daphnidis aspectum; quo se squalentia rura 10

Et desolati prae ruptis frugibus agri

uere nouo reparant, patulosque ad sidera ramos

extollit quercus, quo sudant mella genistae

lyliaque abiecti referunt cadentia uepres

\footnotetext{
${ }^{10}$ De esta manera se lo distingue del primer virrey Luis de Velasco (1550-1564).

${ }^{11}$ Osorio Romero, 1979: 59-60. En Monumenta Mexicana (Zubillaga, MM., t. III p. 498), se lee: Ad aduentum proregis ipsius fabella data breuis atque elegans, communi plausu. Tributa tum praemia scholastica magni pretii: quadringentis aureis stetisse affirmant. Affixa etiam poemata uaria, in lata membra scripta pictaque; eaque tum lecta studiose ab iis, qui conuenerant, tum proregi, quae eminebant; oblata ab iis, qui in pangendo feliciore ingenio praeter caeteros donati essent. Magna illius diei in praesens laetitia, et in posterum memoria fuit. Para los festejos de la ciudad, ver Guía de las actas del cabildo de la ciudad de México, siglo xvi (1970: 698-701).

${ }^{12}$ En el Ms. 1631 esta égloga aparece bajo el número 10. Hemos modificado la numeración por dos razones: 1) la colección está encabezada por la Ecloga in obitu [1], 28 hexámetros pertenecientes a la elegía pastoral Alcón de B. Castiglione; 2) la composición [9] Pro domino Ludouico de Velasco Nouae Hispaniae protege contra Marchiones (1590) no es una égloga.
} 
atque incultus ager pingui flauescit arista. 15

THY. Scilicet hoc hilares quondam cecinere Napeae

cum mundo hoc carmen scripserunt cortice, Daphnis

omnibus una salus atque omnibus unus Apollo est. (Peña)

Égloga por la llegada del Virrey Luis de Velasco.

Coridón/Tirsis

THY. Deja, Coridón, tus cabritas mientras pacen en los campos, que los cantos amebeos celebren a Dafnis. COR. Elevemos a Dafnis hacia los astros, también nos amó Dafnis, gloria egregia y única esperanza para el mundo occidental. THY. Para mí, Coridón, esperanza verdadera, pues mientras el bosque me esconde, la juventud que se dispersa a través de los campos y la ciudad, se hace eco de él llenando todo de sonidos y se hacen eco las Camenas hasta tal punto, Coridón, que ya nada hay en los bosques salvo Dafnis. COR. Muy a menudo bajo la sombra del agudo pino traigo a la memoria la presencia de Dafnis; gracias a él los campos sin cultivo y las tierras desoladas ante la destrucción de los frutos se renuevan con la joven primavera y hacia los astros la encina levanta anchurosas ramas; gracias a él destilan mieles las retamas, las zarzas abatidas reviven los lirios que sucumben y el campo inculto comienza a dorarse con la pingüe espiga. THY. Sin dudas, en otro tiempo, las Napeas, gozosas, cantaron esto, cuando escribieron este verso en la refinada corteza: Dafnis es para todos la única salvación y para todos el único Apolo.

El carácter circunstancial de la égloga se desprende únicamente del título, elemento paratextual que indica el motivo por el cual fue escrita (Ecloga de aduentu proregis Ludouici de Velasco). Al respecto, dice Osuna: “este problema de definición general resulta más complejo debido a la propia tradición del género, que incluía la ocasional infiltración de elementos "circunstanciales", no ya sólo por lo que respecta a las frecuentes dedicatorias de los poemas, sino también por la integración, y a veces confusión, de lo panegírico o lo celebrativo en la trama de la égloga amorosa. Sin necesidad de retrotraerse al modelo virgiliano, baste recordar al respecto los más de seiscientos cincuenta versos (sobre un total de mil ochocientos ochenta y cinco) que Garcilaso dedica a la alabanza de la casa de Alba en su égloga”13.

Si bien, en opinión de Osorio Romero ${ }^{14}$, no hay indicación alguna ni tampoco referencia al año de ingreso del virrey Velasco $(1590,1607)$, dado que esta composición es la única que se repite en el f. 148r, detrás del epigrama Pro domino Ludouico de Velasco Nouae Hispaniae Prorege contra Marchiones, que consigna el año 1590, podría pensarse que fue escrita ese mismo año.

La égloga está construida sobre el modelo virgiliano y en función de un proceso intertextual de alusión que nos lleva a detenernos en la figura de Dafnis, íntimamente relacionada con el género bucólico.

\footnotetext{
${ }^{13}$ Osuna, 2008: 357-358.

14 Osorio Romero, 1989: 258.
} 
El mito de Dafnis aparece en diferentes textos literarios e históricos en los que pueden detectarse diversas versiones ${ }^{15}$. La más antigua hace referencia a un semidios siciliano, hijo de Hermes y una ninfa, que debe su nombre al hecho de haber nacido en un bosque consagrado a las ninfas. Estas le enseñan el arte del pastoreo y del dios Pan recibe la instrucción musical. Luego de enamorarse de la ninfa Nomia, a quien le promete fidelidad eterna, es embriagado por una princesa siciliana que se une a él. Nomia, presa de la cólera, lo priva de la vista.

En la versión de Teócrito el triángulo amoroso es reemplazado por un amor no correspondido y el castigo de la ceguera, por la muerte ${ }^{16}$. Los idilios se caracterizan, además, por desarrollar la vinculación de Dafnis con la naturaleza a través del canto.

Por su parte, Virgilio, en la égloga V, conserva la relación del pastor con la naturaleza y su capacidad para el canto, pero introduce la variante de la muerte inmotivada.

En el poema novohispano del Ms.1631 Dafnis poco tiene que ver con las características del personaje previrgiliano o mítico, dado que el autor no menciona su filiación ni su muerte. El pastor ya aparece en el tríptico dedicado a celebrar el tercer concilio mexicano (Eclogae factae ad consilium mexicanum). En estas tres églogas (2, 3 y 4) se silencia su caracterización como músico y se resalta su presentación como pastor ocupado en sus tareas específicas (postquam Daphnis oues et pascua gramina curat, $E_{c} \log a^{17}$ 2. 6). En la égloga 8 , el jesuita, un tal Peña del que nada se sabe ${ }^{18}$, enfatiza el protagonismo de Dafnis apelando a la epanalepsis ${ }^{19}$ (uocibus alternis alternent carmina Daphnin./COR. Daphnin ad astra feramus, amauit nos quoque Daphnis, Ecloga 8. 2-3) sin hacer referencia explícita a sus actividades pastoriles y musicales. Sin embargo, en términos generales, parece haber tomado como hipotexto la égloga $\mathrm{V}$ de Virgilio $^{20}$ en la que Mopso y Menalcas, cantan respectivamente la muerte y la apoteosis del afamado pastor $^{21}$.

En la égloga neolatina el objetivo de Tirsis y Coridón es alabar a Dafnis, lo cual implica suspender las actividades pastoriles (THY. Linque tuas Coridon tondentes rura capellas/ uocibus alternis alternent carmina Daphnin, Ecloga 8. 1-2). El v. 2, que define el canto de los pastores como un canto amebeo, reelabora el v. 59 de la égloga III del mantuano (alternis dicetis; amant alterna Camenae). Coridón acepta el desafío y da comienzo a la laudatio (Daphnin ad astra feremus, amauit nos quoque Daphnis, 3), ${ }^{22}$ en clara alusión al v. 52 de la égloga V.

\footnotetext{
${ }^{15}$ Cf. El. H.V. X.18; Parth. Erot. XXIX; Diod. Sic. IV.84.

${ }^{16}$ Cf. Id. I y VII.

${ }^{17}$ Utilizaremos Ecloga para referirnos a la égloga novohispana y emplearemos la abreviatura canónica Ecl. para las églogas de Virgilio.

${ }^{18}$ Cf. Osorio Romero, 1989: 263.

${ }^{19}$ Esta figura consiste en repetir al final de una cláusula o frase el mismo vocablo con que empieza.

${ }^{20}$ Efectivamente Virgilio lo presenta como pastor (formosi pecoris custos formosior ipse, Ecl. V 44), y músico, según se deduce del v. 48: nec calamis solum aequiperas, sed uoce magistrum.

${ }^{21}$ Además del precedente teocriteo, hay que tener en cuenta los cantos bucólico-fúnebres de Bión y Mosco.

${ }^{22}$ Las citas de Virgilio siguen la edición de Mynors, 1969.
} 
En Virgilio, Dafnis está asociado al decus (tu decus omne tuis, Ecl.V 34), según se desprende del canto de Mopso $^{23}$; en el poema novohispano se repite la asociación, pero, en este caso, el decus es egregium (Ecloga 8. 4), imagen que, tomada de la épica virgiliana (hunc decus egregium formae atque iuuentae, Aen. VII 473), se "pastoraliza". El pastor, con su presencia, garantiza el decus del mundo bucólico que, en virtud de su ausencia, se vuelve estéril, símbolo de fealdad ${ }^{24}$, y al mismo tiempo representa la esperanza (spes), una esperanza única (unica, Ecloga 8.4) y verdadera (uera, Ecloga 8.5). Si bien en la égloga novohispana no se menciona explícitamente la capacidad de Dafnis para el canto, Tirsis alude a ella a partir de los ecos y las resonancias que provoca en el mundo humano y natural, un mundo que proclama su júbilo (Illum per campos perque urbem fusa iuuentus/ cuncta replens sonitu resonat, resonantque Camenae, Ecloga 8. 6-7), como también lo hace la naturaleza virgiliana en el canto de Menalcas (ipsae iam carmina rupes/ ipsa sonant arbusta, Ecl. V 63-64).

Al referirse al género bucólico, dice Cristóbal: "De la égloga -y de la novela pastoril, luego- una de las características más evidentes es la tendencia idealista y prófuga de la realidad circundante y su instalación en una atmósfera mixta y utópica en la que lo real y contemporáneo se combina con anhelados e imaginados paraísos selváticos”25.

Esta tendencia idealista viene de la mano del tópico de la edad de oro que, en la tradición post-virgiliana neolatina, pertenece a la memoria y a la nostalgia. En la égloga 8, estos tópicos están asociados con la figura de Dafnis. Es de notar que Coridón no incursiona ni en la muerte ni en la deificación del pastor, pero sub tegmine pinus, es decir, a partir del motivo emblemático del arbore sub quadam ${ }^{26}$, recuerda (recolo, Ecloga 8.9) Daphnidis aspectum (Ecloga 8. 10) es decir, la presencia de Dafnis. ${ }^{27}$ Es justamente dicha presencia la que determina un proceso de renovación que deja atrás la fealdad y la esterilidad y da paso a la belleza y a la fertilidad que se actualizan uere nouo (quo se squalentia rura/ Et desolati prae ruptis frugibus agri/uere nouo reparant, Ecloga 8. 10-12) ${ }^{28}$. La transformación que ocasiona Dafnis está planteada en términos de aurea aetas (quo sudant mella genistae /lyliaque abiecti referunt cadentia uepres/ atque incultus ager pingui flauescit arista, Ecloga 8. 13-15). La relación de la edad dorada y el pastor está mediatizada sintácticamente por medio del pronombre relativo quo (vv. 10 y 13), ablativo causal que determina que Dafnis es el agente de quien depende la renovación del entorno natural. Es de notar que las imágenes que aluden al tópico de la aurea aetas son de raigambre virgiliana, pues están tomadas de la égloga IV, tal como se desprende de la ocurrencia de los troncos de encinas que destilan mieles

\footnotetext{
${ }^{23}$ Respecto del empleo de decus en Ecl. IV 11, afirma Colemann, 1991: 134: “decus refers to the marvels of the preceding line and half."

24 Schmidt, citado por Martínez Astorino, 2006.

${ }^{25}$ Cristóbal, 2008: 27.

${ }^{26}$ Dentro de los motivos paisajísticos y musicales fundamentales en la poesía bucólica, la estampa inicial en la que un pastor toca la flauta o canta a la sombra de un árbol se ha vuelto típica. Así lo encontramos en Virgilio: Tityre, tu patulae recubans sub tegmine fagi,/siluestrem tenui Musam meditaris auena./Nos patriae finis et dulcia linquimus arva./Nos patriam fugimus. Tu. Tityre, lentus in umbra,/ formosam resonare doces Amaryllida siluas. (Ecl. I 1-5).

${ }^{27}$ OLD, s.u aspectus (5).

${ }^{28}$ Nótese el empleo de lexemas e imágenes virgilianas (squalentia, G. IV ; uere nouo, Ecl. X 74 y G. I 43, IV 13).
}

91 Marcela A. Suárez. La Ecloga de aduentu proregis Ludouici de Velasco del Ms. 1631...86-95. 
(et durae quercus sudabunt roscida mella, Ecl. IV 30) y los campos dorados por las espigas (molli paulatim flauescet campus arista, Ecl. IV 28) que gradualmente se transforman, según lo expresa el incoativo flauesco. Dafnis, pues, comunica belleza a los campos y a la naturaleza toda ${ }^{29}$.

La alabanza a través del canto de los pastores se da en el presente de la narración. Pero en los vv. 16-17 (Scilicet hoc hilares quondam cecinere Napeae/ cum mundo hoc carmen scripserunt cortice,) Tirsis hace referencia al canto de las ninfas mediante la imagen carmen scripserunt cortice que resulta una clara alusión a los carmina escritos en la verde corteza de un haya por el propio Mopso, en la égloga virgiliana (Immo haec, in uiridi nuper quae cortice fagi/carmina descripsi et modulans alterna notaui, / experiar, Ecl. V 13-15). Este canto que pone fin a la égloga novohispana resulta por demás interesante en función de las siguientes particularidades: a) se ubica en el pasado (quondam); b) recupera desde "otro tiempo" (quondam) la relación canto (cecinere) /poesía (hoc carmen scripserunt) propia del género; y c) está marcado por el eje semántico de la "alegría", que se concentra en el lexema nominal hilares por medio del cual las napeas son caracterizadas y anticipan un mensaje esperanzador.

Si volvemos a la égloga $\mathrm{V}$ de Virgilio, advertimos que, a partir de la apoteosis cantada por Menalcas, Dafnis se convierte en un hombre-dios y adquiere características de intercesor (sis bonus o felixque tuis, Ecl. V 65) ${ }^{30}$. En el poema neolatino el pastormúsico representa la salvación para todos (Daphnis/ omnibus una salus, Ecloga 8. 18). y es predicado como unus Apollo ${ }^{31}$. Esta asociación se justifica no solo porque Apolo es el dios de la música y una divinidad pastoral, sino porque además su nombre está asociado a un sistema religioso y moral que prometía la salvación ${ }^{32}$.

Dafnis es el paradigma del pastor ideal que instaura una edad de oro solo realizable en el marco de una comunidad rural. Es presentado como un personaje por cuya presencia la naturaleza se transforma ${ }^{33}$ y la humanidad resulta beneficiada a causa de su condición de salvador.

Ahora bien, la materia predominante del idilio teocriteo y la égloga virgiliana es la invención de situaciones y personajes dentro de un escenario boscoso, es decir, la ficción. A esto se añade el mito que se mezcla con la ficción, dado que en las églogas los pastores conviven con los dioses. Finalmente, interviene la temática histórica explícita, transferida a la ficción o bajo el velo de la alegoría. Ficción, mito e historia son los tres componentes de lo bucólico que la tradición post-virgiliana retoma. De hecho, los comentaristas virgilianos renacentistas propician la lectura interpretativa de las Églogas. Así Poliziano, en su edición (Opera, Roma, 1471), señala que totus liber

\footnotetext{
${ }^{29}$ En la égloga virgiliana el lamento de Mopso hace hincapié en que, frente a la muerte del pastor, la naturaleza participa del dolor y el duelo. Pales y Apolo abandonan los campos (Ecl. V 34b-35) y solo subsisten plantas estériles y carentes de belleza. (Ecl. V 36-39).

${ }^{30}$ Virgilio utiliza una fórmula propiciatoria propia de la lengua religiosa para encabezar la plegaria al nuevo dios (Nagore, 1991-1992: 126).

${ }^{31}$ Cf. Verg. Aen. II 710.

${ }^{32}$ Grimal s.u.

${ }^{33}$ En la égloga 2 del Ms. 1631 se pone el acento en que la renovación generada por Dafnis adquiere tal magnitud que no faltarán las artes pascendi (19) ni el alimento para los rebaños (ouilibus herbae, 19) y no será necesario el yugo para arar la tierra (forte etiam indigenis soluentur aratra iuuencis, 20).
}

92 Marcela A. Suárez. La Ecloga de aduentu proregis Ludouici de Velasco del Ms. 1631...86-95. 
per allegoriam intellegitur ${ }^{34}$. Luis Vives, por su parte, en su Interpretatio allegorica in Bucolica Virgilii (1537), afirma: Accedit huc quod res ipsae plerisque in locis satis testantur, non simpliciter dici, sed figurate; quo magis miror, Seruium Honoratum nullas allegorias admittere, nisi de agris deperditis: quae aliis multis de rebus manifestissimae sunt ${ }^{35}$.

En este sentido, el autor novohispano, influido por esta corriente de interpretación y tratándose de un poema de circunstancias, pondera el componente ingenioso que entraña el plano de la alusión histórica. ${ }^{36}$ Bajo el velo alegórico de la presencia de Dafnis (Daphnidis aspectus) a la que hacen referencia los pastores de la égloga se esconde la llegada de Luis de Velasco (aduentus proregis), considerado en Nueva España uno de los virreyes más querido y recordado por sus méritos ${ }^{37}$, con quien los integrantes de la Compañía de Jesús mantienen estrechos vínculos y en cuya celebración de bienvenida los estudiantes juegan un papel protagónico:

\section{[...] Perque urbem fusa iuuentus \\ cuncta replens sonitu resonat (Ecloga 8. 6-7)}

\section{Conclusiones}

De acuerdo con lo señalado al comienzo de este trabajo, la égloga como género de circunstancias se desarrolla en los siglos XVI y XVII y adopta los rasgos genéricos más estereotipados (los personajes pastores, los cantos alternos, el espacio natural idealizado) y, sobre todo, los tres componentes de lo bucólico: la ficción, el mito y la historia. Así, pues, los pastores ficcionales conviven con los dioses de la mitología, pero a esta dupla se suma la temática histórica que interviene como fuente de injerencias explícitas, de elementos transferidos a la ficción o bien de situaciones y personajes latentes bajo el velo de la alegoría - "aunque determinar ese contenido oculto siempre sea problemático”-, sostiene Cristóbal ${ }^{38}$.

La Ecloga de aduentu proregis Ludouici de Velasco del Ms. 1631 (BNM) reúne las características propias de un poema de circunstancias y se convierte además en un ejemplo de aplicación de los principios reglados por la Ratio Studiorum: lectura, memorización e imitación. Construida sobre el modelo virgiliano, la composición novohispana es el resultado de la reelaboración de tópicos, motivos e imágenes, dignos de ser imitados ${ }^{39}$. Pero, sin duda, una lectura atenta de todos estos elementos nos ha

\footnotetext{
${ }^{34}$ Mateo Mateo (1991: 328).

35 Según Ijsewijn, 1978, Vives, a lo largo de su carrera de profesor, enseñó notablemente las Églogas y las Geórgicas de Virgilio. Con respecto a las obras de Vives en Nueva España, ver Osorio Romero, 1980.

36 No es menos probable que también haya dejado su impronta la lectura en clave alegórica de la égloga V, propuesta por el humanista español, Luis Vives, quien ve en Dafnis la prefiguración de Cristo.

${ }^{37}$ Luis de Velasco pasa toda su juventud y se arraiga en México. En 1585, a causa de ciertas diferencias con el Marqués de Villamanrique, decide regresar a España. Allí es destinado por Felipe II a la embajada de Florencia. Por Real Cédula de 19 de julio de 1589 es nombrado Virrey de Nueva España para suceder al Marqués contra quien se habían levantado severas acusaciones por su tiranía y codicia. Su desembarco en México origina en el Cabildo, del cual había sido miembro cuatro años antes, una gran satisfacción.

${ }^{38}$ Cristóbal, 2008: 35.

39 No hay que olvidar que los jesuitas tenían la costumbre de confeccionar cartapacios o codices excerptorii, en los que se consignaba el material que podía resultar útil en los ejercicios literarios.
}

93 Marcela A. Suárez. La Ecloga de aduentu proregis Ludouici de Velasco del Ms. 1631...86-95. 
llevado a detenernos fundamentalmente en la figura de Dafnis, en su riqueza estética, en su universalidad, y en las claves de reconstrucción en términos pastoriles de una determinada realidad histórica contemporánea.

\section{Ediciones}

Colemann, Robert (1991), Vergil. Eclogues, Cambridge: Cambridge University "Press. Mynors, Roger (1969), Virgil. Opera, Oxford: Oxford Clarendon Press.

\section{Instrumenta Studiorum}

Glare, Peter (ed.) (1968), Oxford Latin Dictionary, Oxford: Oxford Clarendon Press.

Grimal, Pierre (1997), Diccionario de Mitología Griega y Romana, Buenos Aires: Paidós

\section{Bibliografía}

Cristóbal, Vicente (2008), “Las églogas de Virgilio como modelo de un género". En López Bueno, Begonia. (dir.), La Poesía del Siglo de Oro: Géneros y Modelos, Sevilla: Secretariado de Publicaciones de la Universidad, pp. 23-56 (edición digital en CDRom).

Gil, Eusebio et alii (ed.) (1992), El sistema educativo de la Compañía de Jesús. La Ratio Studiorum, Madrid: Publicaciones de la Universidad Pontificia de Comillas.

González Vázquez, José (1991), “Influencia de Virgilio durante el Prerrenacimiento”, En Sánchez Marín, José - López Muñoz, Manuel (eds.), Humanismo Renacentista y Mundo clásico, Madrid: Ediciones Clásicas, pp.131-154.

Grant, Leonard (1965), Literature and the Pastoral, North Carolina: University of North Carolina Press.

Guía de las actas del cabildo de la ciudad de México (siglo XVI), México: UNAM, 1970.

Ijsewijn, Jozef (1977), Companion to Neo-Latin Studies, Amsterdam: North Holland Publishing Company.

- (1978), "Vives et Virgile”. En Chevallier, Raymond (ed.), Présence de Virgile,Paris: Les Belles Lettres.

Martínez Astorino, Pablo (2006), "Dafnis en la Bucólica V de Virgilio: la alusión compleja y los límites de la identidad”. Auster. La Plata, n 10-11, pp. 89-100.

Mateo Mateo, Ramón (1991), "La interpretación de las claves bucólicas en la poesía renacentista”. Epos, n VII, pp. 313-333.

Nagore, Josefina (1991-1992), "El mito de Dafnis en la égloga V de Virgilio”. Argos. Buenos Aires, $\mathrm{n}^{\circ}$ 15-16, pp.113-130. 
Osorio Romero, Ignacio (1979), Colegios y Profesores jesuitas que enseñaron latín en Nueva España, México: UNAM.

- (1980), Floresta de Gramática, Poética y Retórica en Nueva España (15211767), México: UNAM.

- (1989), Conquistar el eco. La paradoja de la conciencia criolla. México:UNAM.

Osuna, Inmaculada (2008), "La égloga como género de circunstancias”. En López Bueno, Begonia (dir.), La Poesía del Siglo de Oro: Géneros y Modelos. Sevilla: Secretariado de Publicaciones de la Universidad, pp. 357- 381 (Edición digital en CDRom,).

Suárez, Marcela (2014), "Las églogas conmemorativas en el Ms. 1631 de la Biblioteca Nacional de México (BNM). En Assís, Estela- Lobo, Claudia (comp.), Significación y Resignificación del Mundo Clásico Antiguo, Tucumán: Universidad Nacional de Tucumán, pp. 1028-1037.

Van Thiegem, Paul (1966), La littérature latine de la Renaissance. Etude d'histoire littéraire européenne. Genève: Slatkine Reprints.

Zubillaga, Félix (1956-1981), Monumenta Mexicana, tomo I (1570-1580), tomo II (1581-1585), tomo III (1585-1590), tomo IV (1590-1592), tomo V (1592-1596), tomo VI (1596-1599) y tomo VII (1599-1602), Roma: Apud Institutum Historicum Societatis Iesu. 